\title{
O PRINCíPIO dO DIÁlOgO NAS ATIVIDADES EDUCATIVAS COLETIVAS NO PROGRAMA DE RESIDÊNCIA MULTIPROFISSIONAL EM SAÚDE
}

\author{
THE PRINCIPLE OF DIALOGUE IN THE COLLECTIVE EDUCATIONAL
} ACTIVITIES OF HEALTH MULTI-PROFESSIONAL RESIDENCY PROGRAM

\author{
Patricia Tiemy Arakaki Nakashima de Andrade ${ }^{1}$ \\ Estela Márcia Rondina Scandola ${ }^{2}$ \\ Maria de Fátima Bregolato Rubira de Assis ${ }^{3}$
}

\section{RESUMO}

O hospital além de ser um local de atendimento de doentes e seus afins, é também o local propício para que ocorra a Educação Popular em Saúde com os usuários. O presente artigo tem por objetivo analisar as atividades educativas coletivas realizadas no Programa de Residência Multiprofissional em Saúde (PREMUS) a partir do princípio do diálogo da Política Nacional de Educação Popular em Saúde (PNEPS). Metodologia de base qualitativa e análise documental, onde se buscou coletar, organizar e analisar os dados das atas que registraram as atividades educativas, entre julho/2014 a julho/2015 que ocorreram na Unidade de Cuidados Continuados Integrados (UCCI) do Hospital São Julião, sendo utilizado como base para compreensão dos dados, a PNEPS de 2012. Foram encontrados registros de 56 (cinquenta e seis) atas, cujos dados foram organizados em um quadro onde foram observados: frequência semanal das atividades coletivas de Educação em Saúde; os temas das atividades estão, geralmente, relacionados às especificidades de cada área profissional; e, no que se refere ao diálogo, observou-se que há interatividade, mas sem a perspectiva dos princípios da PNEPS.

\footnotetext{
${ }^{1}$ Bacharel em Serviço Social, Especialista em Cuidados Continuados Integrados. Universidade Federal de Mato Grosso do Sul - UFMS. E-mail: patytiemy90@gmail.com.

${ }^{2}$ Doutora em Serviço Social pelo ISCTE-IUL. Escola de Saúde Pública de Mato Grosso do Sul e tutora da Residência Multiprofissional em Saúde do Hospital São Julião. E-mail: estelascandola@ yahoo.com.br.

3 Mestre em Meio Ambiente e Desenvolvimento Regional pela Universidade Anhanguera UNIDERP. Coordenadora do Programa de Residência Multiprofissional em Cuidados Continuados Integrados - PREMUS CCI, no Hospital São Julião. E-mail: fatimabrubira@gmail.com.
} 
Espera-se que este estudo contribua para potencializar o serviço já existente, disseminar para os demais ambientes hospitalares e, sobretudo, reafirmar as possibilidades da Educação Popular em Saúde, como instrumentalidade promotora de conhecimentos e, portanto, indutora de direitos.

PALAVRAS-CHAVE: Educação Popular em Saúde. Hospital. Residência Multiprofissional. Diálogo.

\begin{abstract}
The hospital besides being a place for treatment of sick people, is also a place where occurs Popular Health Education with the users. The purpose of this article is to analyze the collective educational activities performed at the Health Multi-professional Residency Program (PREMUS) starting by the principle of the dialogue of the National Policy of Health Popular Education (PNEPS). Methodology of Qualitative basis and Documental analysis, where it sought to collect, organize and analyze the data from the minutes that recorded the educative activities, between July of 2014 and July of 2015 that happened at the Integrated Continuous Care Unit(UCCI) of the São Julião Hospital, being used as basis to understand the data, the 2012 PNEPS. Records of 56 (fifty-six) minutes were found, whose date were organized in a table where they were observed: weekly frequency of collective health education activities; the themes of the activities are generally related to the specificity of each professional area; and, with regard to the dialogue, it was observed that there is interactivity, but without the perspective of the PNEPS principles. Expected that this essay helps to improve the existing service, to spread to other hospital settings and, especially, reaffirm the possibilities of health popular education, in a hospital, as instrumentality promoted of knowledge and, therefore, inductor of rights.
\end{abstract}

KEYWORDS: Popular Education in Health. Hospital. Multi-professional Residency. Dialogue.

\title{
INTRODUÇÃO
}

Os hospitais são, em si, lugares de presença de doentes, familiares/acompanhantes, trabalhadores em saúde e, quando são de ensino, também de estudantes. É, portanto, um lugar em que ocorrem diversos processos de educação em saúde com maior ou menor estruturação, com evidência ou não de intencionalidades. Nas relações entre os diferentes públicos que convivem no cuidado há possibilidade de ocorrer a Educação Popular em Saúde (EPS) se forem considerados, nas práticas educativas, os seus princípios como: diálogo, problematização, construção compartilhada do conhecimento, emancipação, amorosidade, compromisso com a construção do projeto democrático e popular, como registrado na Política Nacional de Educação Popular em Saúde (BRASIL, 2012).

A Educação Popular no âmbito hospitalar ainda é pouco discutida, pois nascida nos movimentos sociais, tem majoritariamente exercícios na Atenção Primária e é comum afirmar que se trata de processos educativos com usuários do Sistema Único de Saúde (SUS). A Educação Popular que se constituiu, inicialmente, na década de 1950, no Brasil, tem o Serv. Soc. \& Saúde, Campinas, SP v. 16, n. 2 (24), p. 279-300, jul./dez. 2017 E-ISSN 2446-5992 
referencial político-pedagógico delineado e consolidado a partir da história de luta social, tendo como forte evidência o próprio Movimento Sanitário (BRASIL, 2012). Portanto, os hospitais também participam dos mesmos processos sócio-históricos que estão presentes no SUS e, neles, a Educação Popular. A Educação Popular, conforme definição do Ministério da Saúde:

[...] é compreendida como perspectiva teórica orientada para a prática educativa e o trabalho social emancipatórios, intencionalmente direcionada à promoção da autonomia das pessoas, à formação da consciência crítica, à cidadania participativa e à superação das desigualdades sociais (BRASIL, 2012, p. 5).

Mesmo considerando que no âmbito hospitalar há diferentes intensidades de relacionamento com a participação dos sujeitos, é possível considerar que, também a partir desses, repensa-se os hospitais. Pedrosa (2007) relata que as organizações populares, desencadearam um processo de mobilização política junto com o processo de resgate da cultura popular como afirmação desses sujeitos, demarcando a emergência de novos movimentos sociais.

O histórico da EPS é de intensa presença nos processos de participação da sociedade no movimento político de formulação dos marcos históricos da Reforma Sanitária, seja nos antecedentes da VIII Conferência Nacional de Saúde, na Assembleia Constituinte, no texto Constitucional e na organização do Sistema Único de Saúde (SUS), principalmente na participação e controle social (FALEIROS et al., 2006).

O processo de institucionalização vivenciado pela EPS, nesses últimos anos, provocou o desenvolvimento de várias ações referenciadas, sobretudo, na reflexão sobre a importância e significado que as práticas de Educação Popular em Saúde possuem no contexto da gestão participativa e do cuidado integral em saúde (BRASIL, 2012).

As Conferências Nacionais de Saúde de 2004, 2008 e 2011 expressaram, em suas resoluções finais, a necessidade de se aprovar a Política Nacional de Educação Popular em Saúde (PNEPS) e sua implementação. O Conselho Nacional de Saúde aprovou, em 2012, a nova política e o Ministério da Saúde, em 2013, instituiu a mesma por meio da Portaria 2761/2013 (BRASIL, 2013). 
A PNEPS reafirma o compromisso com a universalidade, a equidade, a integralidade e a efetiva participação popular no SUS. Propõe uma prática político-pedagógica que perpassa as ações voltadas para a promoção, proteção e recuperação da saúde, a partir do diálogo entre a diversidade de saberes valorizando os saberes populares, a ancestralidade, o incentivo à produção individual e coletiva de conhecimentos e a inserção desses no SUS (BRASIL, 2012).

Dentre as estratégias da PNEPS está o campo da formação, que conforme o artigo $4^{\circ}$, $\S 2^{\circ}$ : da Portaria que a instituiu, “[...] compreende a ressignificação e criação de práticas que oportunizam a formação dos trabalhadores e atores sociais em saúde na perspectiva da educação popular [...]" (BRASIL, 2013).

Umas das experiências de formação de trabalhadores em saúde em curso hoje no Brasil e com desafios importantes é o Programa de Residência Multiprofissional em Saúde (PREMUS). Esse Programa tem o propósito de capacitar o profissional para trabalhar em equipe, tentando abranger o conjunto de necessidades de saúde da pessoa atendida, humanizar a assistência e promover a integralidade da atenção. Potencializa-se, desta forma, um campo rico de possibilidades e criatividade, o qual reafirma a necessidade de inovar a gestão, a organização da atenção e o protagonismo dos trabalhadores no sistema de saúde (BRASIL, 2005).

É nos PREMUS que ocorrem diferentes práticas educativas envolvendo trabalhadores em saúde, preceptores, tutores, residentes, professores, usuários e seus familiares/cuidadores/acompanhantes. Esse é o caso do PREMUS do Hospital São Julião (HSJ) em Cuidados Continuados Integrados (CCI) que teve início no ano de 2014, no município de Campo Grande/MS.

A modalidade de Cuidados Continuados ocorre diversamente nos países e a literatura internacional referencia que o conceito de "integrated care" é que faz a ligação entre as diferentes experiências, como por exemplo: “cuidados continuados integrados” em Portugal; "atención sócio sanitária" na Espanha; "shared care" y "joint care" no Reino Unido; "vernetzung" na Alemanha; "transmurale zorg" na Holanda; "soins médico-sociaux" na França e "managed care" ou "Transititional care" nos Estados Unidos (GESAWORLD, 2012). Além dos aspectos culturais do cuidado, há de se considerar nos Cuidados Continuados, a estruturação das políticas públicas e a intersetorialidade em cada realidade. 
Dentre os aspectos desse modelo de cuidado em saúde, os objetivos e a operacionalização indicam estratégias semelhantes, quais sejam: orientam-se a dar resposta a situações de necessidades complexas que requerem intervenção de natureza mista, social e de saúde, de forma simultânea ou sequencial. É sempre um cuidado de forma complementar e fortemente articulado para pacientes que apresentam dependência funcional e/ou psicológica temporária ou permanente. Em todas as experiências dos Cuidados Continuados, a capacitação dos trabalhadores, familiares/cuidadores/acompanhantes e dos próprios usuários tem importância estratégica para viabilizar a integralidade do cuidado (GESAWORLD, 2012).

No PREMUS do Hospital São Julião o projeto pedagógico prevê a integração de saberes visando desenvolver competências e conhecimentos gerais, essenciais para o mercado de trabalho e para a construção da cidadania, como a comunicação verbal e escrita, a leitura e compreensão de textos, raciocínio, saúde e segurança no trabalho, bioética, biossegurança; desenvolver competências e conhecimentos relativos a atividades de gestão, autogestão, melhoria da qualidade da assistência, do trabalho coletivo e individual, no processo saúde/doença - competências e conhecimentos específicos relativos à atenção a saúde do paciente (UFMS/HSJ/ESP, 2014).

Considerando o referido projeto pedagógico, nos anos de 2014 e 2015, foram selecionados residentes graduados em 6 (seis) áreas de concentração: 2 (dois) de enfermagem, 2 (dois) de farmácia, 2 (dois) de fisioterapia, 2 (dois) de nutrição, 2 (dois) de psicologia e 2 (dois) de serviço social. No início de cada turma de residentes, são constituídas duas equipes permanentes com um profissional de cada área.

Com as equipes formadas principalmente pelas profissões com forte tendência biomédica, há um processo de tensionamento sobre a Educação em Saúde e seus objetivos. A valorização de práticas focadas no modelo biomédico compromete a possibilidade de encontros que permitam a construção coletiva do saber e transformação da realidade com o abarcamento mais amplo do que as orientações individuais (FRANCO, 2011).

Para os residentes a Educação Popular torna-se um aprendizado permanente e está prevista como prática no processo de ensino-aprendizagem das ações educativas envolvendo diferentes públicos. A inserção da EPS em 2014 desencadeou para o conjunto do PREMUS a 
adoção da troca de saberes, como uma exigência da própria atividade educativa, ou seja, a postura dialógica como centro da ação, cujo pensamento freiriano sobre o diálogo é que ele,

[...] é uma exigência existencial. E, se ele é o encontro em que se solidarizam o refletir e o agir de seus sujeitos endereçados ao mundo a ser transformado e humanizado, não pode reduzir-se a um ato de depositar ideias de um sujeito no outro, nem tampouco tornar-se simples troca de ideias a serem consumidas pelos permutantes (FREIRE, 2005, p. 91).

Sendo um dos princípios da PNEPS, o diálogo é o exercício do encontro de conhecimentos construídos histórico e culturalmente por sujeitos, portanto, o encontro desses sujeitos na intersubjetividade. O diálogo acontece quando cada um, de forma respeitosa, coloca o que sabe à disposição para ampliar o conhecimento crítico de ambos acerca da realidade contribuindo com os processos de transformação e humanização. Contrapõe-se assim, à visão de mundo estática e pessimista, ao afirmar que o mundo e os sujeitos que dele fazem parte e o constroem estão em permanente transformação (BRASIL, 2012).

O diálogo desafia cotidianamente a realidade, a problematiza e contribui com a elaboração de estratégias para superação das problemáticas que se apresentam, ampliando a capacidade crítica sobre a própria realidade. Implica escuta interessada, humildade para aprender, amorosidade para o encontro, esperança na mudança de si, do outro e da realidade. O diálogo é colaboração, troca, interação e se faz numa relação horizontal em que a confiança de um no outro é consequência. Implica um respeito mútuo que o autoritarismo não permite que se constitua. O pensamento crítico de um, não anula o processo de construção do pensamento crítico do outro e os conflitos são explicitados e não silenciados. Não nivela, não reduz um ao outro, não é bate-papo ou conversa desinteressada; a palavra traz a riqueza da história de vida de cada um e seu posicionamento, avaliação e coerência entre o pensar e o agir frente à realidade (BRASIL, 2012).

Essa perspectiva dialógica desafia todas as profissões em saúde e, em especial o cotidiano da função sócio-educativa do profissional de Serviço Social, inserido em uma equipe multiprofissional em âmbito hospitalar. O compromisso ético-político para com a população usuária requer não somente a troca de saberes, sobretudo, dirigir-se ao protagonismo dos sujeitos no mundo a ser transformado.

Embora se reconheça que nos espaços hospitalares as práticas de Educação Popular ainda se restrinjam a projetos pioneiros, o PREMUS do HSJ tem na sua programação diversas atividades educativas e, em especial, a reunião de cuidadores. Para o Serviço Social, essa atividade é um espaço de saúde e o profissional deve intervir no processo de ampliação Serv. Soc. \& Saúde, Campinas, SP v. 16, n. 2 (24), p. 279-300, jul./dez. 2017 E-ISSN 2446-5992 
da cidadania e da democracia, assim como contribuir no maior acesso da população às decisões da saúde, fazendo com que o SUS seja de todos e para todos. A Educação Popular pode possibilitar, então, o desenvolvimento de consciência crítica uma vez que o

[...] incremento de estratégias programadas em equipe possibilita a compreensão da saúde pela sociedade como direito e questão de cidadania, e fortalece o paradigma que considera a saúde um elemento central do desenvolvimento social, econômico e político do país (SARRETA, 2009, p. 59).

Esse pensamento corrobora com os Parâmetros para Atuação do Assistente Social na Política de Saúde (CFESS, 2010) que reafirma a compreensão da determinação social do processo saúde/doença. A dimensão educativa da profissão encontra nos fundamentos teórico-metodológicos da Educação Popular a efetivação da visão transformadora do Serviço Social prevista pelo Projeto Ético Político da categoria (PEREIRA; OLIVEIRA, 2013).

A participação dos profissionais de Serviço Social nas equipes multiprofissionais potencializa as possibilidades de analisar as ações em saúde que ocorrem de forma interdisciplinar e, dentre essas, a Educação em Saúde. Trata-se, portanto, esse artigo, de uma contribuição que a profissão realiza não somente para o PREMUS do HSJ, como também para o SUS e para a Política Nacional de Educação Popular em Saúde, especialmente no debate sobre seu espaço em ambientes hospitalares.

Para isso este artigo tem o objetivo de analisar as atividades educativas coletivas realizadas no PREMUS a partir do princípio do diálogo da PNEPS.

\section{MÉTODO}

Trata-se de um estudo qualitativo de análise documental, realizado na Unidade de Cuidados Continuados Integrados (UCCI) do Hospital São Julião, situado no município de Campo Grande/MS. A opção pela pesquisa qualitativa deu-se pela compreensão que o estudo tem a característica fundamental de ser sócio-histórico e entre a pesquisadora e o objeto de pesquisa, há uma relação de participação no mesmo mundo a ser pesquisado. Assim, o olhar científico sobre a realidade não implica neutralidade, mas a busca permanente de aproximação com o real e com a objetividade (MINAYO, 2010). Ainda conforme a autora, as pesquisas qualitativas são: '

Serv. Soc. \& Saúde, Campinas, SP v. 16, n. 2 (24), p. 279-300, jul./dez. 2017 E-ISSN 2446-5992 
[...] entendidas como aquelas capazes de incorporar a questão do SIGNIFICADO e da INTENCIONALIDADE como inerentes aos atos, as relações, e as estruturas sociais, sendo essas últimas tomadas tanto no seu advento quanto na sua transformação, como construções humanas significativas (MINAYO, 2010, p. 40).

A coleta de dados ocorreu em todas as atas contidas no livro de registro $n^{\circ} 1$ do Hospital São Julião, no período de julho/2014 a julho/2015. Os dados foram organizados em um quadro que permite observar a frequência, temas das atividades com os cuidadores, as áreas profissionais e a presença do princípio do diálogo, conforme modelo do quadro a seguir.

QUADRO I - Matriz de organização dos dados contidos no livro-ata do PREMUS do HSJ

\begin{tabular}{|c|c|c|c|}
\hline Data & Tema & Área profissional & Presença de diálogo \\
\hline & & & \\
\hline
\end{tabular}

Fonte: Livro-ata de registro das reuniões com cuidadores do PREMUS do HSJ. Elaborado pelas autoras.

Para análise desses dados, remeteu-se ao que diz Minayo (2007), ou seja, inicialmente a pesquisadora realizou uma leitura compreensiva do conjunto do material selecionado, de forma exaustiva. Tratou-se de uma leitura de primeiro plano para atingir níveis mais profundos. Em seguida, realizou-se uma exploração do material, extraindo dos registros todas as anotações que pudessem caracterizar o princípio do diálogo, conforme previsto na PNEPS. Por fim, elaborou-se uma síntese com os dados e realizou-se sua interpretação através de uma redação que dialoga com tema e o objetivo. Procurou-se manter o texto conforme o registro das atividades educativas.

A tarefa do pesquisador qualitativo consiste, assim, em interpretar os conceitos provenientes do campo de pesquisa, para dar-lhes uma forma que se inscreve, ela própria, na tradição científica (DESLAURIERS; KÉRISIT, 2012).

A pesquisa qualitativa enfatiza o campo, não apenas como reservatório de dados, mas também como uma fonte de novas questões. O pesquisador qualitativo não vai a campo somente para encontrar respostas para suas perguntas, vai também, para descobrir questões, surpreendentes sob alguns aspetos, e geralmente, mais pertinentes e mais adequadas do que aquelas que ele se colocava no início (DESLAURIERS; KÉRISIT, 2012).

A análise de dados, reconhecida como uma fase de máxima importância, pois ocupa na pesquisa qualitativa o encontro entre a realidade e as fundamentações teóricas, norteou a pesquisadora na busca por novos referenciais para compreender os dados. 
Para a realização do presente artigo, produzido no âmbito da conclusão da Residência Multiprofissional em Saúde do Hospital São Julião, o mesmo foi aprovado pelo parecer 1.568.080, do Comitê de Ética em Pesquisa com Seres Humanos da Universidade Federal de Mato Grosso do Sul - CEP/UFMS.

\section{RESULTADOS}

No livro de registro $\mathrm{n}^{\mathrm{o}} 1$ do Hospital São Julião destinado à reunião de cuidadores foram encontrados os registros de 56 (cinquenta e seis) atas no período de julho/2014 a julho/2015 que estão entre as páginas 14 a 69 (verso). Esse dado indicou que há regularidade nas reuniões, acontecendo sempre às segundas-feiras, e essa atividade compõe a programação da semana padrão do PREMUS do Hospital São Julião, ou seja, é inerente às atividades dos residentes.

Os registros estão em um livro-ata que é de livre acesso aos residentes e aos demais trabalhadores da instituição, compondo um acervo histórico dessa atividade. A iniciativa de um livro de registro foi tomada desde o início da implantação da PREMUS, é uma das fontes mais significativas do desenvolvimento das ações da Unidade de Cuidados Continuados Integrados/HSJ.

Os registros das atividades educativas foram denominados de atas. Embora não seja o mais adequado, já que não se trata de um documento de valor jurídico, que consiste em registro narrativo fidedigno e decisões do que passou em uma assembleia, sessão ou reunião, o conteúdo dos registros guarda importantes informações sobre as atividades coletivas com os cuidadores. A denominação ata é possível que decorra do nome da atividade que é "reunião de cuidadores". A denominação de reunião de cuidadores evidencia que há um conceito polissêmico do que seja uma reunião, pois essa geralmente é utilizada nas instituições para tomada de decisões o que não ocorreu em nenhum destes 56 registros analisados. A característica do evento em análise é de um encontro visando Educação em Saúde.

Assim, mesmo sendo reunião e ata, as características dos registros encontrados estão mais próximas de atividades coletivas de Educação em Saúde e relatório desses encontros, ou seja, a nomenclatura não determinou sua forma. 
Ao observar os registros, fica evidente que se trata de um de relato pedagógico de uma das atividades do PREMUS do HSJ, o qual poderia ser chamado de relatório ou registros de atividades, pois é um documento descritivo de cada atividade.

Contém em seu texto inicial um padrão que identifica a data, o tema a ser tratado no dia e o ministrante. A palavra ministrante representa uma modalidade de Educação em Saúde bastante afinada com a prática transmissora, em um primeiro olhar. Conforme Aurélio, ministrar significa: prestar, fornecer, administrar e conferir (AURÉLIO, 2017).

Ao observar o nome dos ministrantes percebeu-se que pertencem alternadamente entre as duas equipes de residentes do primeiro ano. Todas as profissões participam de um rodízio entre equipes e também entre residentes. As reuniões de cuidadores ocorrem sob a responsabilidade de um residente, e foi possível observar, que o registro foi realizado por outro residente.

A leitura dos relatos leva a perceber, que os residentes desempenham várias atividades. O Ministrante realizou tanto as técnicas da Educação em Saúde quanto o aprofundamento do conteúdo, a outro residente coube o registro da atividade e à equipe, a que pertence o ministrante, participação no debate e organização do ambiente.

A denominação que se aproxima dos diferentes papéis desempenhados é o de facilitador, caracterizado como aquele que é o intermediador, dinamizador e responde aos questionamentos e também expõe os conhecimentos, ou seja, desenvolve as potencialidades do grupo. Mudar de ministrante para facilitador não seria apenas substituir a palavra, mas uma compreensão mais pedagógica do que já está sendo realizado, muito embora possa ser observado nos registros que há momentos em que se "ministram" conteúdos. Assim, a mudança de denominação poderá também ser indutora de posturas pedagógicas mais dialógicas.

Considerando o rodízio das equipes, subtende-se que toda semana é um novo encontro e, que, portanto, não acontece uma sequência dos temas tratados anteriormente. Cabe considerar que, ao observar a assinatura dos participantes, nota-se mudança entre as pessoas destinatárias, ou seja, há alguns que já participaram antes, assim como há pessoas novas. Reafirma-se a ideia de que semanalmente é constituído um novo grupo podendo os temas, então, serem repetidos para os residentes, sem necessariamente repetir para os pacientes e familiares/cuidadores/acompanhantes.

Dos registros de reuniões com cuidadores, perceberam-se duas composições: 
Preceptor, residente e cuidador: a não presença do paciente acontece quando as reuniões são direcionadas aos cuidadores, cujo tema pode trazer algum constrangimento. Embora não explicitado, o processo de decisão sobre a participação ou não da pessoa adoecida nas atividades educativas, é possível que tenha a ver com a decisão de viabilizar um espaço de fala onde os cuidadores possam expressar às dificuldades enfrentadas, os sentimentos, a sobrecarga, as dificuldades familiares e financeiras. Nesse sentido, a não presença do paciente é uma forma de preservação para ambos.

Preceptor, residente, cuidador e paciente: ocorre quando nas reuniões são tratados temas de administração de medicação, alimentação saudável, rede de atendimento, direitos sociais, ou seja, temas referentes ao manejo do cuidado com o paciente, o autocuidado e/ou de cidadania.

No entanto, é possível observar que também em assuntos diversos não houve a participação dos usuários internados e, por isso, há de se observar melhor o processo decisório sobre a composição das reuniões, pois não tem registros no livro-ata.

Com relação ao temário, pelos registros, na maioria das atas, não houve descrição de como são feitas as escolhas dos temas. Em 3 (três) atas houve registro de que foi solicitado aos participantes o tema que deveria ser tratado nos próximos encontros:

[...] foi questionado, qual assunto melhor a ser tratado na próxima reunião. (Livro 1, p. 61V);

[...] Por fim, os cuidadores foram questionados sobre sugestões de temas a serem tratadas nas próximas reuniões [...] (Livro 1, p. 62V);

[...] fala que a próxima reunião será a mesma e pergunta sugestões, falam que debater sobre a incontinência urinária é importante (Livro 1, p.63V);

Observa-se que na primeira e na segunda ata não houve registro se houve ou não sugestões de temas. Já na última sugestão não houve identificação de quem solicitou o tema incontinência urinária, ou seja, se foi pelos familiares/cuidadores/acompanhantes ou pelos próprios residentes. Cabe ressaltar que observando a semana seguinte, o tema sugerido não foi abordado.

O fato de ter encontrado três registros sobre levantamento do temário ao final de cada reunião dentre as 56 (cinquenta e seis) atas analisadas pode indicar três possibilidades: a) o registro da demanda não foi realizado; b) não houve levantamento de expectativas. Pela 
observação das pesquisadoras, não há momento de discussão das necessidades de Educação em Saúde nos encontros educativos; e, c) no único caso em que houve registro de sugestão para o próximo tema, a ata seguinte indicou que o mesmo não foi trabalhado. Conforme explicitado anteriormente, as equipes do PREMUS revezam-se semanalmente, ou seja, afirma novamente a ideia de que não há continuidade da atividade de uma semana para outra.

Sobre o temário trabalhado nas reuniões foi possível organizar, a partir da profissão dos ministrantes, o Quadro II.

QUADRO II - Demonstrativo do temário por área profissional

\begin{tabular}{|c|}
\hline ENFERMAGEM \\
\hline $\begin{array}{l}\text { Cuidados para prevenir úlcera por pressão; Cuidados básicos de Enfermagem - higiene das } \\
\text { mãos, higiene oral e exercícios reabilitadores; Dispositivos assistenciais; Higienização das } \\
\text { mãos; Posicionamento no leito; Cuidados básicos de Enfermagem; Fortalecimento do vínculo } \\
\text { dos cuidadores; Estresse, causas e prevenção; Cuidados com a pele e prevenção de } \\
\text { feridas/úlcera; Orientações fonoaudiólogas para família do paciente afásico. }\end{array}$ \\
\hline FARMÁCIA \\
\hline $\begin{array}{l}\text { Administração e armazenamento de medicamentos; Isolamento e precauções; Orientação } \\
\text { sobre indicações e interações de chás com medicamentos; Cuidados com a medicação; Troca } \\
\text { de experiência entre cuidadores do CCI; Armazenamento de medicamentos em domicílio; } \\
\text { Erros ao tomar remédios via oral; Hipertensão; uma reunião sem título. }\end{array}$ \\
\hline FISIOTERAPIA \\
\hline $\begin{array}{l}\text { Ginástica laboral; A importância do trabalho multiprofissional; A importância do exercício } \\
\text { físico; Mobilização; Alongamentos; Laboral; Mudança de decúbito e transferência; Cuidados } \\
\text { com a coluna; Mobilização, alongamento e fortalecimento. }\end{array}$ \\
\hline NUTRIÇÃO \\
\hline $\begin{array}{l}\text { Nutrição e hipertensão; Constipação; "10 passos para alimentação saudável e importância das } \\
\text { vitaminas"; Como montar um prato saudável e prevenção de Doenças crônicas não } \\
\text { transmissíveis (DCNT); Isolamento de contato; Nutrição em alterações gastrointestinais } \\
\text { (diarreia e constipação); Orientação nutricional na diabete; Dietas hospitalares; Higienização } \\
\text { das mãos. }\end{array}$ \\
\hline PSICOLOGIA \\
\hline $\begin{array}{l}\text { Jogos; Família e sobrecarga do cuidador; Reabilitação cognitiva; Motivação; Sobrecarga do } \\
\text { cuidador; Significado do cuidado e do cuidador; O papel do cuidador; Depressão; Fases do } \\
\text { luto. }\end{array}$ \\
\hline SERVIÇO SOCIAL \\
\hline $\begin{array}{l}\text { Estatuto do Idoso; O cuidar do cuidador; Humanização; O cuidado e o cuidador; Áreas de } \\
\text { convivência; Benefícios assistenciais e previdenciários; Cuidar, cuidado e vínculo; Definindo } \\
\text { direitos e deveres; Benefícios; Cuidando do cuidador. }\end{array}$ \\
\hline
\end{tabular}

FONTE: Livro-ata de registro das reuniões com cuidadores da REMUS do HSJ. Elaborado pelas autoras. 
Ao analisar os temas percebeu-se que eles se repetem, embora com pequenas alterações na descrição. Significa que são escolhidas as necessidades de Educação em Saúde a partir dos residentes, e esses se baseiam no conjunto das demandas recorrentes e/ou se referem às relações com os cuidados diretos com os pacientes.

Outro fato é que o temário de cada profissão está, geralmente, relacionado à especificidade das categorias, o que pode levar à análise que nas atividades educativas coletivas, os residentes ainda não realizam integração multiprofissional, tanto no planejamento quanto na execução das reuniões.

A diversificação das temáticas nas reuniões, de certa forma, propicia aos seus participantes - cuidadores, pacientes, residentes e trabalhadores - acesso a informações de diferentes áreas do conhecimento, para além de suas necessidades expressadas.

Quanto ao princípio "Diálogo" da PNEPS, houve grande dificuldade de identificação, uma vez que nos relatos não está evidenciado a dinamicidade dos encontros. Por isso, considerou-se para análise os fragmentos de registros.

A primeira evidência de diálogo foi a presença permanente da formação de roda. Essa estratégia é de fundamental importância na Educação Popular em Saúde, pois possibilita uma interação partilhada de saberes. Warschauer (2001) afirma que a roda permite trocas que se relacionam entre o saber criativo individual e grupal de forma que possam ser construídos:

[...] o cuidado mútuo, a escuta sensível, o acolher e ser acolhido, a paixão de aprender e ensinar, de ensinar e aprender, a paciência no falar e ouvir, a amorosidade na convivência, a tolerância nas diferenças, o prazer estético partilhado, o respeito durante os conflitos, a coragem de ver-se no outro, de olhar para ele e para si, o formar-se formando... (WARSCHAUER, 2001, p. 300)

Na roda, o próximo passo é a apresentação dos participantes, onde é solicitado o nome, que identifique quem é cuidador e nos casos dos residentes, a profissão. Percebeu-se que não é solicitado do cuidador a identificação de sua profissão. Nesse momento, observa-se um comprometimento no espaço dialógico, pois está estabelecida uma relação de poder, que conforme Foucault (1984) ocorre quando alguém possui um saber a mais que o outro, possui um poder em relação ao outro. Quando os residentes se apresentam em suas respectivas profissões, implica que este é detentor de um conhecimento técnico-científico, estabelecendo assim, a hierarquização de saberes sobre o cuidador, cujo histórico profissional é desconsiderado.

Serv. Soc. \& Saúde, Campinas, SP v. 16, n. 2 (24), p. 279-300, jul./dez. 2017 E-ISSN 2446-5992 
No que se refere à forma de trabalhar o tema na reunião, os registros apontaram que há duas formas de iniciarem a discussão:

- Inicia-se o conteúdo, por meio de apresentação de figuras, vídeos ou slides, conforme pode ser observado nos trechos a seguir:

[...] a cada imagem das úlceras apresentadas a [...] trouxe a participação dos familiares/cuidadores, a qual realizou as orientações necessárias para se evitar úlcera por pressão [...] (Livro 1, p. 14)

[...] inicialmente a abordagem foi a transmissão de um vídeo [...] (Livro 1, p. 17)

[...] Foi ministrado um vídeo educativo sobre hipertensão e seguida a exposição dos cuidados com a alimentação [...] (Livro 1, p. 20)

[...] inicialmente foi abordagem o tema de educação alimentar e nutricional através de uma apresentação em slides [...] (Livro 1, p. 38)

Apesar da utilização da tecnologia em seu favor, Bordenave (1983) retrata que a utilização da moderna Tecnologia Educacional com seus complicados multimeios nada mais é que um veículo sofisticado de mera transmissão.

Quando o ministrante utiliza imagens, vídeos e slides, este expõe o conhecimento técnico-científico existente antes de ouvir o grupo que passa a guiar a discussão e constitui o saber como verdade. Mesmo que a interação ocorra posteriormente, o que foi estabelecido como certo e errado induz a construção da discussão no grupo. O conhecimento, assim, não é coletivo, e tem a característica da pedagogia transmissora.

- $\quad$ Outra forma é pela tentativa de trazer o conhecimento dos cuidadores e/ou pacientes por meio de trabalhos em grupos e perguntas. Conforme pode ser observado nos trechos a seguir, a proposta de trabalho grupal é sempre na busca de horizontalizar e exercitar o diálogo:

[...] foi solicitado para que os participantes se dividissem em dois grupos e que com a utilização de revistas e canetas as pessoas expressem o que para elas significa o termo humanização. [...] (Livro 1, p. 31)

[...] Dividiu os presentes em duas turmas, onde eles deveriam definir o que entendem e o que sabem sobre os direitos e deveres dos pacientes e cuidadores enquanto internados no Hospital São Julião. Tendo uma turma definindo direitos e, a outra, deveres. Os cuidadores elucidaram as conclusões a que chegaram. [...] (Livro 1, p. 57)

[...] Dividiu os participantes em 2 grupos, para responderem: "o que causa estresse" e "como prevenir o estresse". Foi dado um tempo para os grupos 
responderem, depois foi aberto a fala para cada grupo sobre as respostas [...] (Livro 1, p. 59)

[...] foram divididos em dois grupos para discutir o tema: Erros ao tomar remédios via oral. Em seguida foi escolhido um orador de cada grupo relatando as conclusões formadas pelo grupo. [...] (Livro 1, p. 60)

[...] os cuidadores foram divididos em grupos para conversarem sobre as coisas que os deixem com medo, raiva, tristeza. [...] (Livro 1, p. 66)

[...] Os participantes foram divididos em 2 grupos para responder questões sobre higienização das mãos com verdadeiro ou falso [...] (Livro 1, p. 69)

Quando o ministrante utiliza de pequenos grupos, percebe-se que há intenção nítida de que seja mais participativo e que ocorra o conhecimento compartilhado. Os pequenos grupos também possibilitam que os participantes do processo educativo desenvolvam vínculos e, compartilhando suas ideias realizem a compreensão de problemáticas singulares como sendo da particularidade do processo saúde-doença. Os impactos do adoecimento, desta forma, sejam para os cuidadores, na vida familiar e na comunidade são discutidos de forma mais coletiva.

$\mathrm{Na}$ mesma perspectiva de busca de diálogo inicial, percebeu-se que uma das formas utilizadas foi estimular os participantes de forma direta com questões norteadoras sobre o tema da atividade educativa, conforme pode ser observado:

[...] foi solicitado para que as pessoas falassem qual lei que conhece para atendimento ao idoso [...] (Livro 1, p. 18)

[...] A cada participante foi perguntado o que é família, a cada um que respondia segurava uma ponta do barbante. Um grande nó foi feito. Este nó foi sendo desfeito por cada indivíduo, a medida que falava sobre como poderia melhorar a própria família. [...] (Livro 1, p. 22)

[...] Ministrante questionou aos participantes se esses tinham hábito de consumir chás, e se os mesmos faziam ou sabiam de utilização para algum fim específico, e assim teve início uma conversa em roda sobre a utilização dos chás. [...] (Livro 1, p. 29)

[...] abordado questionamento acerca do cuidar. Foi definido pelos participantes: dar cuidado, ser responsável, ficar do lado, acompanhar, saber que pode contar sem superproteger ou sufocar; zelar pela vida do outro; dar atenção, atender necessidades na medida do possível [...] (Livro 1, p. 36)

[...] a ministrante começou um diálogo com o grupo de cuidadores para saber os hábitos de atividades físicas dos cuidadores. [...] (Livro 1, p. 52) 
A perspectiva de questionamento direto com todos os participantes do grupo ocorre quando este é de menor tamanho, não chegando a 20 (vinte) pessoas. Essa forma de trabalho não diminui a possibilidade de desenvolvimento de vínculo e consciência crítica sobre os impactos sócio-psico-econômicos do adoecimento, no entanto, o desafio dessa técnica está na postura dos facilitadores (residentes) para que não se transforme em uma relação de perguntaresposta. Exige para isso, além do conhecimento teórico-metodológico, a postura éticopolítica de estar junto na horizontalidade da construção do saber.

É possível que dentre os participantes da atividade educativa haja pessoas com diferentes conhecimentos que possam contribuir com o grupo e, assim as respostas não necessitam ser somente do educador, como ocorreu em um dos encontros.

[...] Foram respondidas perguntas e questionamento que foram surgindo de acordo com os levantamentos. Pontos chaves apresentados: - Por que contribuir com INSS?; - O que é Beneficio de Prestação Continuada (BPC)?; - Quem pode receber BPC?; - Auxílio-doença; - Quando o auxílio doença deixa de ser pago (Livro 1, p. 45)

As experiências dos cuidadores e pacientes com os benefícios sociais da previdência e da assistência social compõem um conjunto de saberes e informações que enriquecem todas as profissões participantes do PREMUS e, com isso, possibilita agregar às outras categorias conteúdos de conhecimento para além do Serviço Social.

As diferentes formas de diálogo que foram estabelecidas nas reuniões de cuidadores, a que parte da fala dos participantes, está mais em sintonia com os princípios da Educação Popular posto que, considera inicialmente o conhecimento prévio existente no grupo, como também estabelece o momento da fala.

A metodologia que mais se assemelha com as executadas pelos residentes é a metodologia conhecida como Pedagogia da Problematização, Bordenave (1983) entende que o aluno detecta os problemas reais e busca para eles soluções originais e criativas para sua transformação social.

Além disso, outras formas de interações foram identificadas, como, por exemplos: a prática das atividades ocorridas no leito e atividades físicas:

[...] Todos os cuidadores participaram das atividades propostas, sendo a última praticada no leito com ajuda e demonstração dos próprios cuidadores. Sendo o encontro, finalizado com orientações e esclarecimentos. (Livro 1, p. 21)

[...] foi solicitados que cada um realizasse um alongamento conforme conhecimento de cada um [...] (Livro 1, p. 46) 
O que também se observou é que nas reuniões ocorre, ao final, um momento em que os participantes, especialmente os cuidadores, recorrem ao ministrante para tirar dúvidas, conforme pode ser observado nos trechos a seguir:

[...] sanaram dúvidas dos familiares, cuidadores e profissionais que estavam fazendo parte da reunião [...] (Livro 1, p. 17)

[...] dúvidas foram sanadas dos cuidadores. (Livro 1, p. 20)

[...] abriu um espaço para dúvidas e/ou maiores esclarecimentos por partes dos participantes da reunião e foi realizada as orientações devidas e pertinentes. (Livro 1, p. 30)

[...] Para finalizar o ministrante deixou um espaço para os participantes tirar suas dúvidas [...] (Livro 1, p. 37)

[...] ao final ela abriu para dúvidas do grupo no qual foram todas sanadas antes de encerrar a reunião. (Livro 1, p. 44)

[...] Por fim a coordenadora da reunião esclareceu as dúvidas. [...] (Livro 1, p. $67 \mathrm{~V})$

[...] perguntou se houve dúvidas, respondeu aos questionamentos feitos pelos cuidadores [...] (Livro 1, p. 69V)

Considerando todo processo do diálogo, este deveria acontecer em uma perspectiva crítica de construção do conhecimento, de novos saberes, que parte da escuta do outro e da valorização dos seus saberes e iniciativas, contrapondo-se à prática prescritiva, ocorreu na maioria das vezes, como um bate-papo ou conversa. Ao remeter novamente a Pedagogia da Problematização de Bordenave (1983) observa-se que os residentes detectam os problemas de forma coletiva, no entanto ainda não buscam ou não registram soluções originais e criativas para resolução destes problemas.

\section{CONSIDERAÇÕES FINAIS}

As análises documentais permitem afirmar que nas unidades hospitalares é possível realizar atividades educativas com diferentes públicos. Significa que, mesmo sendo os ambientes hospitalares de vieses autoritários e, a maioria dos cuidados, esteja centrada na doença, quando o fundamento da integralidade é considerado, as possibilidades de Educação 
em Saúde se constituem em um rico temário que propicia diálogo com a realidade dos pacientes e seus conviventes.

No caso do Hospital São Julião não somente a ambiência propicia atividades educativas coletivas, como também a organização da semana-padrão impulsiona a sistematização da Educação em Saúde. Os objetivos de trabalhar com os familiares/cuidadores/acompanhantes desafiam o Processo da Educação Popular em Saúde no ambiente hospitalar.

É imprescindível evidenciar que todas as informações do livro-ata foram consideradas e a análise em profundidade dos registros permite afirmar que os cuidadores, residentes, pacientes e trabalhadores da instituição vinculados ao CCI participaram das atividades educativas que propiciaram informações e reflexões com diferentes temáticas. As atividades educativas coletivas que, a princípio, tinham como destinatários os cuidadores são, em si também atividades educativas para os próprios residentes, pois fazem a experiência do conhecimento compartilhado sobre os temas específicos das profissões. Mesmo observando que há pouca interdisciplinaridade nos registros as atividades coletivas fazem avançar o conhecimento de uma área com a outra, sendo necessário problematizar a necessidade de planejamento, execução e avaliação das atividades de forma transdisciplinar.

No projeto pedagógico do PREMUS é previsto aos residentes desenvolverem a integração dos saberes, ou seja, práticas educativas individuais e coletivas que considerem o diálogo como centralidade da ação. No entanto, cabe ressaltar que esses profissionais egressos das universidades, podem não ter vivenciado a Educação Popular e, com isso, desconhecem os fundamentos como também não experienciaram outras práticas educativas que não sejam aquelas com as características da pedagogia transmissora. Nesse contexto torna-se um desafio investir na formação dos residentes em Educação em Saúde e, neste caso, na EPS, já que é considerada como uma atividade de relevância no PREMUS.

Os registros das atividades educativas podem evidenciar a dinamicidade das reuniões, seus conteúdos, bem como oportunizar aos residentes o desenvolvimento da escrita reflexiva. O registro minucioso possibilita identificar todas as informações tratadas na reunião de cuidadores, sobretudo compreender todas as estratégias utilizadas pelo facilitador para a realização da atividade.

Ao se tratar da Educação Popular em Saúde reconhece-se que na construção dialógica do conhecimento todos os saberes são importantes e, mesmo com as relações de poder estabelecidas no hospital, há que considerar os saberes de todos os participantes do cuidado, 
valorizando as estratégias definidas coletivamente entre os trabalhadores e/ou residentes e os familiares/cuidadores/acompanhantes. Uma vez que está se construindo um saber coletivo tudo que é posto deve ser dado como relevante.

$\mathrm{O}$ residente que realiza o relato tem importância fundamental para que a atividade educativa possa ser um momento de construção do conhecimento, produzindo assim um contexto histórico-social, sendo que a situação vivenciada possibilita chegar a referenciais teóricos aprofundados pelos residentes e disparados por todos os participantes. Possibilita que os sujeitos envolvidos sejam protagonistas para uma transformação social, de um conhecimento compartilhado.

Observou-se também nas atividades educativas coletivas analisadas que estas se constituem em um repensar para a instituição, posto que é de extrema importância na concepção de um hospital que produz saúde e que repensa suas práticas do cuidado. Conceber a Educação em Saúde como um processo que ocorre de forma permanente no ambiente hospitalar para além das atividades educativas individuais e coletivas desafia em ser uma meta a ser buscada não somente pelo PREMUS, mas para todo o Hospital São Julião.

Nessa perspectiva, a inserção dos demais trabalhadores da instituição torna-se estratégica visando constituir um ambiente educador e, esse grupo tem a mesma relevância e é necessário que a universalização do acesso ao conhecimento seja integralizada.

Sobre o nome das atividades educativas, percebeu-se, não se tratar de uma reunião de cuidadores, posto que não são tomadas decisões sobre algum assunto, ou seja, a melhor denominação seria encontros coletivos de saúde e esses podem acontecer em todos os ambientes do hospital.

Construir objetivos para as atividades de Educação em Saúde, na perspectiva da Educação Popular, requer a sua ampliação para atuar sobre as diferentes necessidades dos públicos que compõem os ambientes hospitalares. A multiprofissionalidade existente no hospital e a interdisciplinaridade desafiada no PREMUS constituem-se em potencialidades para que os processos educativos sejam diversificados e respondam às problematizações para possíveis transformações sociais.

O princípio do diálogo da PNEPS analisado nas atividades educativas coletivas demonstrou que há uma intencionalidade de interação e integralização dos saberes. Ao observar os métodos utilizados, percebe-se que os todos os envolvidos neste processo estão Serv. Soc. \& Saúde, Campinas, SP v. 16, n. 2 (24), p. 279-300, jul./dez. 2017 E-ISSN 2446-5992 
em constante construção do conhecimento, seja por meio da transmissão ou pela troca de ideias, todos estão agregando novas percepções.

E neste sentido, é importante ressaltar que a presente análise valeu-se dos registros das reuniões em livro ata e que estes podem não retratar as atividades em seus detalhes e objetivos, de forma que os princípios da PNEPS podem ter sido contemplados, mas descritos sob a ótica da área responsável pelo registro e, portanto, não contemplada a metodologia utilizada.

No processo de compreensão do diálogo é notória a necessidade que este seja estabelecido entre os residentes; os residentes e demais trabalhadores; as profissões; os saberes; os internados, cuidadores, acompanhantes, ou seja, todos os públicos que influenciam, são influenciados e participam das atividades educativas. Nas análises realizadas percebeu-se que há pouca utilização de elementos educativos culturais como música, dança, teatro, contação de histórias e dentre outros que tanto poderiam contribuir com o conhecimento coletivo.

Por fim, espera-se que este estudo contribua para potencializar o serviço já existente, disseminar para os demais ambientes hospitalares e, sobretudo, reafirmar as possibilidades da Educação Popular em Saúde como instrumentalidade promotora de conhecimentos e, portanto, indutora de direitos.

Recebido em 07.07.2017 - Aprovado em 26.12.2017

\section{REFERÊNCIAS}

AURÉLIO, Dicionário. Disponível em: <https://dicionariodoaurelio.com/ministrar> Acesso em: 02 mar 2017.

BRASIL. Ministério da Saúde. Política Nacional de Educação Popular em Saúde. Brasília: DF, 2012. Disponível em: 〈http://www.crpsp.org.br/diverpsi/arquivos/PNEPS-2012.PDF> Acesso dia 10 jan 2017.

BRASIL. Ministério da Saúde. Gabinete do Ministro. Portaria n. 2.761, de 19 de novembro de 2013. Institui a Política Nacional de Educação Popular em Saúde no âmbito do Sistema Único de Saúde (PNEPS-SUS). Disponível em: 
<http://bvsms.saude.gov.br/bvs/saudelegis/gm/2013/prt2761_19_11_2013.html> Acesso dia 10 jan 2017.

BRASIL. Ministério da Saúde. Secretaria de Gestão do Trabalho e da Educação em Saúde. I Seminário Nacional da Residência Multiprofissional em Saúde. Brasília - DF, 2005.

BORDENAVE, J.E.D. Alguns fatores pedagógicos. OPS. Brasília, 1983. Disponível em: <http://www.fo.usp.br/wp-content/uploads/EAlguns.pdf> Acesso dia 15 abr 2017.

CONSELHO FEDERAL DE SERVIÇO SOCIAL - CFESS. Parâmetros para atuação de assistentes sociais na saúde. Brasília: CFESS, 2010. Disponível em:

<http://www.cfess.org.br/arquivos/Parametros_para_a_Atuacao_de_Assistentes_Sociais_na_ Saude.pdf> Acesso dia 10 jan 2017.

DESLAURIERS, J. P.; KÉRISIT, M. O delineamento de pesquisa qualitativa. A Pesquisa Qualitativa: enfoques epistemológicos e metodológicos. Editora Vozes. $3^{\text {a }}$. Edição.

Petrópolis, 2012.

FALEIROS, V.; VASCONCELlOS, L. C. F.; SILVA, J. F. S.; SILVEIRA, R. M. G.; A construção do SUS: histórias da Reforma Sanitária e do processo participativo. Brasília: Editora do Ministério da Saúde, Secretaria de Gestão Estratégica e Participativa, 2006. FRANCO, T. A. V.; SILVA, J. L. L.; DAHER, D. V. Educação em Saúde e a Pedagogia Dialógica: uma reflexão sobre grupos educativos na Atenção Básica. Informe-se em promoção da saúde, v.7, n.2.p.19-22, 2011. Disponível em:

<http://www.uff.br/promocaodasaude/grpos\%20ed.pdf>. Acesso em 31 mai 2017.

FREIRE, P. Pedagogia do oprimido. Rio de Janeiro: Paz e Terra, 2005.

FOUCAULT, M. Microfísica do poder. Organização, Introdução e Revisão Técnica de Roberto Machado. 4.ed. Rio de Janeiro: Edições Graal, 1984.

GATTI, B. A. Grupo focal na pesquisa em Ciências Sociais e Humanas. Brasília: Líber Livro Editora, 2005.

GESAWORLD. Projeto: Bases para a criação e desenvolvimento de uma Rede de Cuidados Continuados no Estado do Mato Grosso do Sul: E2. P4. Modelo de Cuidados Continuados e Estratégias básicas para dar impulso a criação e desenvolvimento do novo modelo. São Paulo: Gesaworld, 2012. Não publicado

MINAYO, M. C. S. O desafio do conhecimento: pesquisa qualitativa em saúde. $12^{\mathrm{a}}$ ed. São Paulo: HUCITEC, 2010. 
MINAYO, M. C. S. (org). Pesquisa social. Petrópolis: Vozes, 2007.

PEDROSA, J. I. S. Educação Popular no Ministério da Saúde: identificando espaços e referências. In: BRASIL. Ministério da Saúde. Secretaria de Gestão Estratégica e Participativa. Departamento de Apoio à Gestão Participativa. Caderno de Educação Popular e Saúde. Brasília: Ministério da Saúde, 2007.

PEREIRA, A. A.; OLIVEIRA, N. H. D. de. Reflexões acerca do assistente social em sua dimensão educativa com famílias. Serviço Social e Saúde, v. 12, n. 1, 2013. Disponível em: $<$ http://www.cfess.org.br/arquivos/Parametros_para_a_Atuacao_de_Assistentes_Sociais_na_ Saude.pdf> Acesso dia 10 fev 2017.

SARRETA, F. O. Educação permanente em saúde para os trabalhadores do SUS. 2009. 232 f. Tese (Doutorado em Serviço Social) - Programa de Pós-Graduação em Serviço Social, Universidade Estadual Paulista Campus de Franca, Franca, 2009.

\section{UNIVERSIDADE FEDERAL DE MATO GROSSO DO SUL-UFMS/HSJ/SES. Projeto}

\section{Pedagógico do Programa de Residência Multiprofissional ou em Área Profissional da}

Saúde. Campo Grande: MS, 2014. Não publicado

WARSCHAUER, C. Rodas em rede: oportunidades formativas na escola e fora dela. Rio de Janeiro: Paz e Terra, 2001. 